\title{
MÉTODOS MOLECULARES NO DIAGNÓSTICO NÃO INVASIVO DA REJEIÇÃO AGUDA EM TRANSPLANTES RENAIS.
}

\author{
Molecular methods in non-invasive diagnosis of acute rejection in kidney transplants.
}

\author{
Gabriel Joelsons ${ }^{1}$, Tuany Domenico ${ }^{1}$, Roberto Ceratti Manfro ${ }^{1,2}$
}

\begin{abstract}
RESUMO
O transplante renal é atualmente o tratamento de escolha para pacientes com doença renal crônica em estágio terminal. Dentre as complicações decorrentes do transplante, a rejeição aguda é considerada uma das principais, sendo a biópsia o padrão ouro para seu diagnóstico. Por ser um procedimento invasivo e potencialmente deletério, buscam-se novos marcadores para o diagnóstico desse quadro. As ferramentas diagnósticas não invasivas apresentam diversas vantagens, que incluem principalmente a possibilidade de uso frequente e sequencial, facilitando a avaliação do estado imune do receptor. Nesta revisão, apresentam-se os métodos e as vantagens dos mesmos que estão sendo empregados atualmente na pesquisa em transplantes renais, a reação em cadeia da polimerase em tempo real, os micro-arranjos de DNA e mais recentemente os micro-RNAs. Existe a expectativa de que os microarranjos e microRNAs venham a desempenhar um papel crucial no transplante de órgãos em assuntos relacionados à identificação de mecanismos moleculares de rejeição aguda, injúria crônica, efeito de toxicidade das drogas imunossupressoras e tolerância. O desenvolvimento de técnicas moleculares capazes de fornecer um painel da atividade imunológica responsável pela agressão ao enxerto de forma não invasiva sugere a possibilidade futura de otimização e individualização do tratamento imunossupressor. Para a realização deste trabalho foi utilizada a busca em bases de dados internacionais (PUBMED, Web of Knowledge) através dos descritores "Transplante de Rim", "Rejeição de Enxerto" e "Técnicas e Procedimentos Diagnósticos" e foram selecionados apenas estudos de periódicos indexados sendo referidos os estudos de maior importância clínica ou histórica na área.
\end{abstract}

Descritores: Transplante de Rim; Rejeição de Enxerto; Técnicas e Procedimentos Diagnósticos.

Instituição:

${ }^{1}$ Programa de Pós-Graduação em Medicina: Ciências Médicas da Faculdade de Medicina da Universidade Federal do Rio Grande do Sul.

${ }^{2}$ Serviço de Nefrologia do Hospital de Clínicas de Porto Alegre. Porto Alegre, RS. Brasil.

Correspondência:

Roberto Ceratti Manfro

Serviço de Nefrologia do Hospital de Clínicas de Porto Alegre

Av. Ramiro Barcelos 2350 - CEP 90040-003, Porto Alegre/RS, Brasil

Fax: 5551 3359-8121

E-mail: rmanfro@hcpa.ufrgs.br

\section{INTRODUÇÃO}

O transplante renal é atualmente o tratamento de escolha para pacientes com doença renal crônica (DRC) em estágio terminal. Entretanto, pacientes a ele submetidos permanecem acometidos por episódios de disfunção aguda e crônica dos enxertos, as quais têm diversas etiologias, sendo que os episódios de rejeição aguda (RA) são considerados uma das principais complicações e podem ter impacto na função e na sobrevida dos enxertos. ${ }^{1} \mathrm{O}$ diagnóstico da rejeição aguda, assim como dessas outras causas de disfunção é baseado fundamentalmente nos resultados da análise histológica do tecido renal obtido por biópsia. Entretanto, existem diversos problemas com esse método, por exemplo, a infecção pelo vírus polioma, que pode apresentar um quadro histológico muito semelhante ao da rejeição aguda e, muitas vezes, é difícil diferenciar a rejeição crônica da nefrotoxicidade por inibidores da calcineurina. Adicionalmente, a biópsia renal é um método invasivo, caro, com problemas de representatividade, variabilidade de interpretação e associado a complicações que podem ser bastante sérias. ${ }^{2}$

Os métodos auxiliares ao diagnóstico da RA são igualmente pouco precisos. As dosagens de creatinina, níveis séricos de fármacos imunossupressores e métodos de imagem padecem de 
falta de acurácia adequada para o diagnóstico das disfunções de causa parenquimatosa. Isso evidencia a clara necessidade do desenvolvimento de novos métodos diagnósticos, preferencialmente não invasivos, que possam ser utilizados como biomarcadores dos processos inflamatórios, tóxicos e fibróticos que acometem enxertos renais, auxiliando ou até mesmo substituindo o diagnóstico histopatológico.

\section{Novos biomarcadores em transplante renal}

Um biomarcador é definido como uma substância ou característica usada como indicador do estado biológico normal ou patológico, que pode ser objetivamente medida, e que reflete a ação das intervenções terapêuticas sobre a atividade da doença. ${ }^{3}$ Existem diversos tipos de biomarcadores que diferem predominantemente em seu objetivo, podendo ser: (a) preditivos, para a identificação do risco de doença; (b) de rastreamento: para a identificação de doença sub-clínica; (c) diagnósticos para o reconhecimento de doença; (d) de estadiamento: para a categorização da gravidade da doença; (e) de prognóstico utilizados para a predição do curso da doença ou da resposta terapêutica. ${ }^{4}$

$\mathrm{Na}$ prática dos transplantes renais, os biomarcadores são usados corriqueiramente para o acompanhamento da evolução do enxerto. Utilizamos marcadores de função e agressão ao enxerto, como a creatinina, proteinúria, métodos de imagem, anticorpos anti-HLA e biópsias protocolares ou de vigilância. Entretanto, esses biomarcadores utilizados na clínica apresentam deficiências tais como, falta de sensibilidade, serem tardios, invasivos e algumas vezes caros.

Adicionalmente, há situações nas quais existe necessidade de maior refinamento diagnóstico, como os enxertos sob risco aumentado de rejeições, os estados de imunossupressão excessiva, a ocorrência de fibrose tecidual, propiciar segurança da minimização e conversões da terapia imunossupressora e a identificação do desenvolvimento de tolerância aos aloantígenos. Atualmente, o processo de desenvolvimento e validação de biomarcadores é bastante complexo e visa assegurar que o teste em questão tenha utilidade clínica. ${ }^{5}$ Vide Figura 1.

Figura 1. Etapas de desenvolvimento e validação de biomarcadores
1. Seleção do biomarcador (ou conjunto de biomarcadores)
2. Coorte de validação
Estudo piloto
Validação metodológica
Validação clínica
3. Coorte de aprendizado
4. Coorte de confirmação
5. Confirmações por outros grupos
6. Ensaios guiados (multicêntricos)
7. Impacto nos resultados clínicos

Neste trabalho, revisaremos o estado atual do desenvolvimento dos biomarcadores moleculares em desenvolvimento para uso em transplantes de órgãos sólidos, em especial os transplantes renais.

\section{Rejeição aguda dos enxertos renais.}

A RA clássica é caracterizada pela rápida diminuição da função do enxerto, que é atacado pelo sistema imune do hospedeiro, o qual reconhece e ataca antígenos presentes no órgão do doador. Conforme demonstrado de forma sucinta na Figura 2, o processo de rejeição inicia-se pelo reconhecimento dos antígenos de histocompatibilidade (aloantígenos) do doador pelos linfócitos $\mathrm{T}$ do receptor. ${ }^{6} \mathrm{O}$ reconhecimento ocorre em órgãos linfóides secundários, onde células apresentadoras de antígeno (monócitos/macrófagos, células dendríticas e células B) estimulam e ativam linfócitos $\mathrm{T}$, que entram em expansão clonal e migram para o enxerto onde irão exercer sua função efetora. No mecanismo de rejeição celular, após a estimulação dos linfócitos, pela interação do TCR com o Complexo Principal de Histocompatibilidade $(\mathrm{CPH})$ juntamente com moléculas de adesão e co-estimulação, os complexos TCR/CD3 e CD4 ou CD8 tornam-se fisicamente associados e ativam várias enzimas intracelulares denominadas tirosino-quinases. Estas elevam a concentração de cálcio intracelular e ativam várias proteínas citoplasmáticas regulatórias denominadas fatores de transcrição. Entre esses fatores, destacam-se NF-kB, Oct-1 e NFAT (fator nuclear de células $\mathrm{T}$ ativadas), que se ligam a regiões regulatórias dos genes de várias citocinas como interleucinas IL-2 e IL-4, interferon-y e TNF- $\alpha$. A ativação da imunidade celular seguida da resposta do tipo hipersensibilidade tardia com a ativação de monócitos/macrófagos e linfócitos citotóxicos parece ser o mecanismo final da agressão celular ao enxerto.

\section{Figura 2 - Rejeição Aguda}

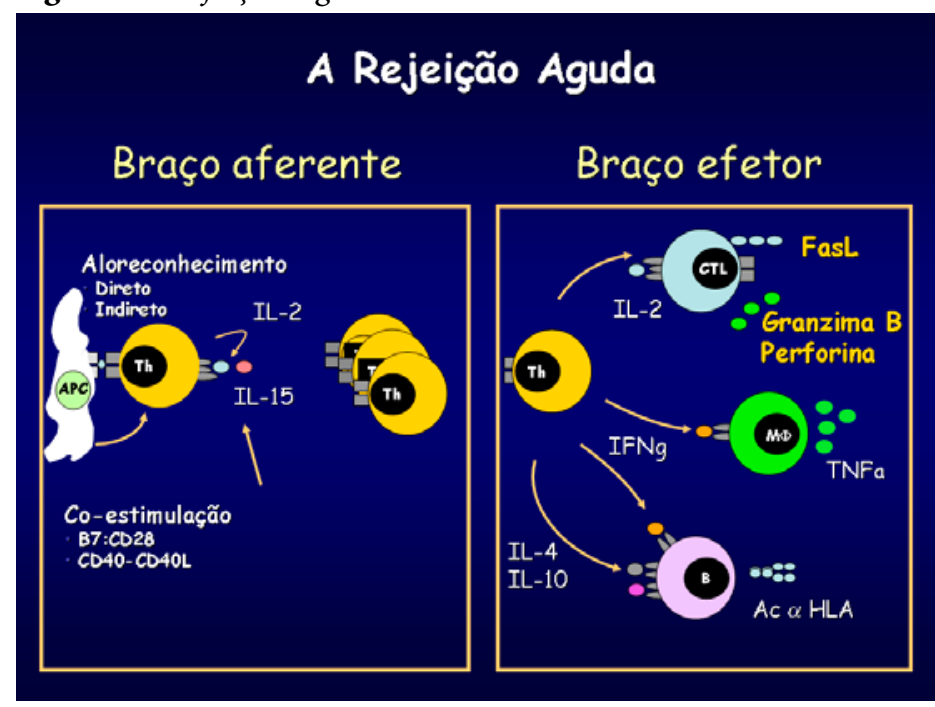

Os linfócitos T CD8+, ou citotóxicos, são os principais efetores do reconhecimento e ataque das células-alvo. Os mediadores citolíticos melhor descritos são a perforina e a granzima, que ficam estocadas no citoplasma desses linfócitos, em grânulos semelhantes aos lisossomos e, quando as células são ativadas, migram para a membrana citoplasmática e fundem-se a ela, liberando os grânulos em direção à célula-alvo. Em decorrência do ataque citolítico, a célula alvo pode morrer por necrose (caracterizada por ruptura da membrana plasmática e destruição das organelas) ou apoptose (caracterizada por condensação da cromatina, fragmentação do DNA e bolhas de membrana com citoplasma condensado). Outra via de ataque citotóxico utilizada pelas células T CD8+ é a indução de morte celular via interação $\mathrm{Fas} / \mathrm{Fas}$ ligante, que leva à apoptose das célulasalvo.,8 Outros mecanismos ocorrem na chamada rejeição humoral, ou mediada por anticorpos. De forma resumida, nesse tipo de rejeição ocorre ativação de linfócitos $\mathrm{B}$ que se diferenciam em plasmócitos, via estimulação por mediadores solúveis (interleucinas) produzidos por linfócitos T CD4+. Os anticorpos reconhecem sequências específicas de aminoácidos 
presentes em antígenos HLA expressos na superfície das células endoteliais do enxerto, ativam a cascata do complemento e levam assim a dano da microcirculação do enxerto..$^{9,10}$

Mais recentemente foi demonstrado que a injúria causada pelo processo de isquemia e reperfusão no enxerto renal conduz à ativação do sistema imune, levando a processos capazes de afetar a integridade celular, acreditando ser um dos principais responsáveis pela lesão inicial do enxerto e por mediar, em longo prazo mudanças estruturais, incluindo a fibrose intersticial. ${ }^{11}$ A Interleucina (IL)-17 foi originalmente descrita e clonada por Rouvier et al. e, subsequentemente, renomeada para IL-17A. ${ }^{12}$ Essa fração é considerada o protótipo da família das IL-17. A identificação dessa nova família de citocinas designou uma nova linhagem celular T CD4 efetora, as Th17. Essas células produzem principalmente a IL-17A e a IL-17F, enquanto as demais células da resposta imune inata produzem os outros membros da família. Essa linhagem parece ter evoluído como um braço do sistema imune adaptativo especializado para uma proteção reforçada contra agentes não cobertos completamente pelas células Th1 ou Th2. ${ }^{13,14}$

A IL-17 é uma citocina pleiotrópica com múltiplas funções, entre elas direcionar diversos tipos celulares como as células endoteliais e epiteliais, fibroblastos, macrófagos e outras células que promovem inflamação tecidual por diferentes caminhos, além de coordenar a inflamação do tecido, induzindo a expressão de citocinas pró-inflamatórias (tais como IL-6 e TNF), quimiocinas (tais como KC, MCP-1 e MIP-2) e metaloproteases de matriz, que intervêm na infiltração e destruição dos tecidos ${ }^{10}$ além de mediar o recrutamento de neutrófilos, a IL17 também promove a granulocitopoiese através da indução do fator de crescimento de colônia granulocítica (G-CSF) e fator de célula tronco (SCF), potencializando também a fagocitose e a citotoxidade dos neutrófilos. ${ }^{15}$

Estudos indicam que o mRNA IL17 e a proteína aumentam em episódios de rejeição aguda em pacientes transplantados renais, hepáticos e pulmonares. Caldwell e colaboradores mostraram que a lesão de reperfusão de isquemia hepática que contribui para o aumento da imunidade específica ao aloantígeno por diversos mecanismos, conduz também ao aumento de células Th17. ${ }^{16}$ Estudos em modelos de murinos que foram induzidos à rejeição aguda renal identificaram uma elevação dos níveis de mRNA da IL-17 e consequentemente sua proteína dois dias póstransplante, também detectado em amostras de urina e tecidos de pacientes com rejeição renal aguda. ${ }^{17}$

Caracteristicamente, o diagnóstico de rejeição aguda em enxertos renais é baseado na identificação anatomopatológica de infiltrados de células mononucleares em fragmentos renais obtidos por biópsias de enxertos com disfunção. O diagnóstico é feito através da padronização por um consenso internacional de nomenclaturas e critérios específicos para a caracterização histológica de rejeição do órgão, denominado classificação Banff, ${ }^{18}$ no qual a rejeição mediada por células $\mathrm{T}$ ou a rejeição mediada por anticorpos é diagnosticada com base em regras empíricas e as lesões são graduadas de maneira semi-quantitativa. Essa análise histológica, a partir de uma biópsia renal, é considerada o "padrão-ouro" no diagnóstico de rejeição do enxerto. Porém, uma vez que essa metodologia é baseada na remoção de fragmentos corticais de natureza focal intra-enxerto, essa não pode ser considerada uma técnica muito sensível, além de estar associada às complicações como sangramento, fístula arteriovenosa e perda do enxerto; também é um método bastante agressivo e dispendioso.

O diagnóstico histopatológico da rejeição correlaciona-se com a resposta ao seu tratamento e com os desfechos do enxerto. Porém, sua acurácia nunca pôde ser validada devido ao fato de não haver outra metodologia independente da avaliação da existência de rejeição. ${ }^{2,19}$ Existem diversos aspectos negativos dessa técnica diagnóstica. Entre eles, destacam-se: (a) graduação das lesões feita de maneira arbitrária; (b) variação de representatividade entre fragmentos das punções de biópsia renal; (c) concordância entre diferentes avaliadores de 10-50\% em relação à gradação das lesões e de $45-70 \%$ relacionado ao diagnóstico; (d) reprodutibilidade intra-observador de aproximadamente $80-85 \% .{ }^{20}$

A rejeição aguda subclínica (RASC) é diagnosticada por biópsias protocolares em enxertos com função estável. A exemplo do que vem ocorrendo com as rejeições agudas clinicamente manifestas, as RASC vêm apresentando incidência decrescente à medida que regimes imunossupressores mais potentes são utilizados. ${ }^{21} \mathrm{Nessa}$ situação, por definição, os enxertos têm função estável e ocorre a presença de infiltrados linfo-monocitários característicos de rejeição aguda. ${ }^{22}$

Médicos com experiência e conhecimento no uso clínico das drogas imunossupressoras e que sejam capazes de manejar adequadamente os atuais métodos diagnósticos são, em geral, capazes de reconhecer e tratar os eventos decorrentes da imunossupressão insuficiente, a rejeição aguda, ou da imunossupressão excessiva, a nefrotoxicidade e as infecções. $\mathrm{O}$ exercício da prática clínica, assim como o que foi aprendido em modelos experimentais, comprova a noção empírica de que as rejeições devem ser diagnosticadas com a maior precocidade possível e que essa precocidade tem implicação na reversibilidade do processo de rejeição. No entanto, são comunssituações de curso silencioso, nas quais faltam métodos diagnósticos apropriados e que, portanto, cursam sem diagnóstico, muitas vezes levando a processos irreversíveis. A crescente eficácia das medicações imunossupressoras evidenciou duas condições de importante impacto negativo na sobrevida dos transplantes renais, quais sejam o aumento significativo nos casos de nefropatia pelo vírus polioma ${ }^{23} \mathrm{e}$ a nefrotoxicidade pelos inibidores da calcineurina. ${ }^{24}$ Por conseguinte, a comunidade de transplante está atualmente direcionada a desenvolver estratégias seguras, em propiciar baixa incidência de rejeição, de nefrotoxicidade e de infecções virais em um balanço entre a eficácia da imunossupressão e seus efeitos colaterais. Em paralelo, busca-se alcançar a situação ideal, ou seja, o desenvolvimento de tolerância aos antígenos do transplante.

Assim sendo, levando-se em consideração as limitações do método "padrão-ouro" atual e a necessidade de métodos diagnósticos acurados que propiciem diagnósticos precoces, preconiza-se que os ensaios não invasivos serão capazes de se tornar ferramentas para monitorização frequente e efetiva no período pós-transplante. Idealmente, esses ensaios devem ser capazes de detectar: [1] inflamação subclínica do enxerto; [2] fibrose intersticial e atrofia tubular subclínicas; [3] glomerulopatia do transplante subclínico e [4] agressão mediada por anticorpos. A base lógica para a detecção desses processos em estágio subclínico serve para a intervenção prévia ao dano causal da perda crônica de função e/ou insuficiência do enxerto. ${ }^{25}$

\section{Métodos Moleculares no Diagnóstico da Rejeição Aguda}

O sistema histopatológico de uso corrente, a classificação Banff, possui critérios que se correlacionam com desfechos, 
porém as decisões são arbitrárias e devem ser revistas por novos métodos de avaliação transcripcional, presentemente denominada transcriptômica, que dessa forma representa referencial independente. ${ }^{26} \mathrm{~A}$ aplicação clínica das análises moleculares é também pertinente para que o entendimento de todo o transcriptoma forneça conhecimentos mais aprofundados das bases mecanísticas das disfunções dos enxertos, da rejeição e de possíveis estados de tolerância. Estratégias complementares utilizando-se biomarcadores baseados na amplificação de ácidos nucléicos devem possibilitar no futuro o desenvolvimento do manuseio personalizado tanto do ponto de vista diagnóstico como de orientação terapêutica. ${ }^{27}$

Em etapas subsequentes, essas ferramentas deverão identificar condições patológicas sem a necessidade de procedimentos invasivos e assim propiciar uma avaliação confiável do estado imune do receptor, permitindo a individualização da terapia imunossupressora. $\mathrm{O}$ aperfeiçoamento do entendimento dos mecanismos da resposta aloimune levou a que fossem testados marcadores moleculares de genes candidatos para a avaliação do transplantado renal. Posteriormente, novos estudos focaram em padrões de expressão em testes não invasivos de fluidos biológicos de acesso facilitado, como urina e sangue periférico. ${ }^{28-31}$

As ferramentas diagnósticas não invasivas apresentam diversas vantagens, que incluem principalmente a possibilidade de uso frequente e sequencial, facilitando a avaliação do estado imune do receptor. Assim sendo, os parâmetros moleculares poderão vir a servir para direcionar a minimização da imunossupressão e sua individualização. Abordagens moleculares que incorporem um conjunto de marcadores podem vir a funcionar não apenas como uma metodologia substitutiva para o procedimento invasivo da biópsia tecidual, como também poderá fornecer informações preditivas, diagnósticas e prognósticas e prover a compreensão da fisiopatologia das diferentes causas de disfunção do enxerto. ${ }^{32}$

Adicionalmente, conforme já demonstrado em estudos clínicos, as avaliações moleculares propiciam a vantagem inequívoca de detectar o processo de agressão em sua fase de montagem, antes que tenha ocorrido deterioração funcional. Da mesma forma, as perturbações moleculares devem também preceder as alterações histológicas. ${ }^{25,32}$ Embora essa última afirmação possa ser vista como uma vantagem, ela é também um empecilho à validação adequada dos testes moleculares no cenário clínico em que a biópsia é usada como o padrão-ouro.

Os métodos moleculares surgiram como potencialmente adequados para o diagnóstico de disfunções dos enxertos renais. Nas fases iniciais do desenvolvimento clínico dos testes moleculares, em especial da reação em cadeia da polimerase em tempo-real (RT-PCR), ela foi utilizada em tecido de aloenxertos, sendo poste ${ }^{\star}$ riormente aplicados em amostras não invasivas, sangue periférico e células do sedimento urinário. Os métodos atualmente empregados na pesquisa em transplantes renais são a RT-PCR, os micro-arranjos de DNA e mais recentemente os micro-RNAs.

Diversos estudos demonstraram a utilidade da mensuração da expressão gênica de genes relacionados ao ataque citolítico ao enxerto em tecido renal, ${ }^{28}$ células do sangue periférico ${ }^{29}$ e células do sedimento urinário. ${ }^{30,31}$ Mais recentemente, alguns estudos utilizando a técnica de microarranjos também foram capazes de predizer episódios de rejeição aguda baseados em padrões de expressão gênica em relação a pacientes normais e com outras causas de disfunção. ${ }^{26,32,33}$ Assim sendo, fica claro que até o presente momento, os métodos moleculares foram testados predominantemente para o diagnóstico de RA de transplantes renais. (Figura 3)

Figura 3 - Principais metodologias aplicadas

\begin{tabular}{|c|c|c|c|c|c|}
\hline Autor (ref) & Ano & $\mathbf{n}$ & Amostras & Metodologia & Marcadores \\
\hline Vasconcellos (29) & 1998 & $31 / 25$ & Tecido e SP & PCR competitiva & Perforina, Granzima B e FasL \\
\hline Van Kooten (17) & 1998 & 08/jun & Tecido & PCR competitiva & IL-17 \\
\hline $\operatorname{Li}(30)$ & 2001 & $24 / 22$ & Urina & PCR competitiva & Perforina, Granzima B \\
\hline Sarwal (46) & 2003 & $67 / 50$ & Tecido & Microarranjos & $\mathrm{n} / \mathrm{a}$ \\
\hline Flechner (32) & 2004 & $44 / 44$ & Tecido e SP & Microarranjos & $\mathrm{n} / \mathrm{a}$ \\
\hline Dias (38) & 2004 & $35 / 35$ & Tecido & RT-PCR & Perforina, Granzima B, FasL \\
\hline Muthukumar (8) & 2005 & $83 / 83$ & Urina & RT-PCR & FOXP3, CD25, CD3 e Perforina \\
\hline Renesto (31) & 2007 & $72 / 72$ & Urina & RT-PCR & TIM3 e IFN-gamma \\
\hline Brouard (33) & 2007 & $91 / 91$ & SP & Microarranjos & $\mathrm{n} / \mathrm{a}$ \\
\hline Bunnag (42) & 2008 & $83 / 83$ & Tecido & RT-PCR & FOXP3 \\
\hline Aquino-Dias (28) & 2008 & $48 / 35$ & Tecido, SP e Urina & RT-PCR & Perforina, Granzima B, FasL, PI9 e FOXP3 \\
\hline Manfro (37) & 2008 & $160 / 115$ & Tecido, SP e Urina & RT-PCR & TIM3 \\
\hline Sui (55) & 2008 & 03/mar & Tecido & microarranjos, RT-PCR & 20 miRNAs diferentes \\
\hline Reeve (26) & 2009 & $186 / 143$ & Tecido & Microarranjos & $\mathrm{n} / \mathrm{a}$ \\
\hline Anglicheau (52) & 2009 & $33 / 32$ & Tecido e SP & microarranjos, RT-PCR & miR-142-5p, miR-155, miR-223 \\
\hline Newell (40) & 2010 & $100 / 100$ & SP e Urina & microarranjos, RT-PCR & $\begin{array}{l}\text { Granzima B, Perfori- } \\
\text { na, PI9, FoxP3, CTLA4, TGFB, CTGF, IP10, MIG e CXCR3 }\end{array}$ \\
\hline Viklicky (43) & 2010 & $64 / 64$ & Tecido & RT-PCR & $\begin{array}{l}\text { TGF-B, TNF-a, MCP1, RANTES, FOXP3, Granzima B, Per- } \\
\text { forina e HMOX1 e outros }\end{array}$ \\
\hline Lorenzen $(58)$ & 2011 & $88 / 81$ & Urina & RT-PCR & miR-10a, miR-10b, miR-210 \\
\hline Anglicheau (44) & 2012 & $114 / 114$ & Urina & RT-PCR & $\begin{array}{l}\text { Vimentina, HGF, Fibronectina, Perforina, TGF-B1, TIMP-1, } \\
\text { Granzima B e outros }\end{array}$ \\
\hline
\end{tabular}




\section{PCR em tempo real}

PCR em tempo real é uma reação quantitativa altamente sensível e que permite a quantificação de transcritos raros e de pequenas variações na expressão gênica. O sistema da PCR em tempo real é baseado na detecção e quantificação de um repórter fluorescente, cuja quantidade aumenta de forma diretamente proporcional às quantidades do produto molecular amplificado na reação. Pelo registro da quantidade de fluorescência emitida a cada ciclo é possível monitorar a reação da RT-PCR durante sua fase exponencial, onde o aumento significativo dos produtos amplificados correlaciona-se com a quantidade inicial do produto (template) específico, marcador de um gene em particular, a ser avaliado. $^{34}$

A técnica quantitativa eliminou a variabilidade inerente à técnica da PCR convencional semi-quantitativa e permitiu a quantificação confiável de produtos de PCR na rotina clínica. Atualmente, essa técnica é comumente utilizada para determinar a expressão gênica de mRNAs e seus níveis de expressão. As análises podem ser absolutas, como no número de cópias de mRNA pela comparação a uma curva padrão, ou relativas a um calibrador pela análise por curva padrão ou pelo método $2-\Delta \Delta \mathrm{Ct} .{ }^{35}$

Diversos mecanismos celulares que dizem respeito à sobrevivência, crescimento e diferenciação são refletidos por padrões alterados de expressão gênica ea habilidade de quantificar níveis transcripcionais de genes específicos é de fundamental importância para qualquer pesquisa sobre a expressão gênica. A PCR em tempo real (RT-PCR) é um método de amplificação enzimática in vitro de sequências definidas de cDNA, podendo ser utilizada para comparar níveis de mRNA em diferentes populações ou amostras para caracterizar padrões de expressão de mRNAs em patologias específicas. A PCR convencional não proporciona resultados quantitativos, exceto na modalidade denominada PCR competitiva, trabalhosa, artesanal e de difícil reprodutibilidade. ${ }^{36}$

O primeiro estudo a avaliar a expressão gênica em amostras não invasivas, no caso o sangue periférico foi de Vasconcellos e colaboradores, em 1998. Nesse estudo, correlacionou-se a expressão gênica de transcritos de mRNA pela técnica de PCR competitiva no tecido e sangue periférico, tendo sido analisadas as expressões dos genes Perforina, Granzima B e Fas-Ligante. Foi encontrado que a expressão gênica dessas moléculas que codificam o ataque citolítico nas células mononucleares do sangue periférico correlaciona-se com sua expressão intra-enxerto. Adicionalmente, encontrou-se elevada acurácia diagnóstica para o evento rejeição aguda pela análise das quantificações desses genes, espacialmente nas análises combinadas. $^{29}$

As análises em urina foram inicialmente realizadas por $\mathrm{Li}$ e colaboradores, que avaliaram quantificações mRNA dos genes da Perforina e Granzima B extraído de células do sedimento urinário, correlacionando-as às quantificações obtidas a partir do tecido obtido por biópsias renais, novamente utilizando a técnica de PCR competitiva. Os autores encontraram que níveis elevados dos transcritos desses genes na urina foram capazes de diferenciar pacientes normais de pacientes com rejeição aguda, propiciando assim esse diagnóstico de forma não invasiva. ${ }^{30}$ Posteriormente, em trabalho oriundo do mesmo grupo, Muthukumar e colaboradores, também avaliando o mRNA extraído de células do sedimento urinário, dessa vez pela técnica de RT-PCR, demonstraram elevada expressão do gene Forkhead Box 3 (FOXP3), e foram capazes de distinguir pacientes com rejeição aguda de pacientes com doença crônica do enxerto renal e de biópsias normais. Interessantemente nesse estudo, a análise dos níveis de mRNA de FOXP3 foi capaz de identificar os pacientes em risco de perda de enxerto nos seis meses posteriores ao episódio de rejeição aguda. ${ }^{8}$

Mais recentemente, Renesto e colaboradores descreveram a utilização de uma molécula especificamente expressa em células Th1 diferenciadas chamada TIM3 como marcadora de rejeição aguda a partir do RNA extraído de células do sedimento urinário. Níveis elevados de TIM3 foram encontrados em pacientes com RA, comparados a outras condições clínicas, mais uma vez sugerindo o uso dessa metodologia como uma ferramenta não invasiva promissora para avaliação das disfunções de enxertos renais.31 Essa mesma molécula foi estudada de forma pareada em tecido, células do sedimento urinário e do sangue periférico por Manfro e colaboradores em pacientes com DGF e com disfunção aguda de enxertos renais. Nos casos de DGF, a avaliação dos parâmetros diagnósticos para RA apresentou acurácia de 100\% nos dois compartimentos periféricos na diferenciação de necrose tubular aguda (NTA). Nos casos de disfunção aguda do enxerto, as acurácias ficaram em torno de $90 \%$ na diferenciação entre rejeição aguda, nefrotoxicidade por inibidores de calcineurina, IFTA e rins normais. $^{37}$

Aquino-Dias e colaboradores analisaram moléculas de ataque citolítico como a Perforina, Granzima B, Fas-ligante e uma serpina proteinase - PI-9 além do gene de células T-regulatórias - FOXP3. Esse estudo avaliou a utilidade dessa metodologia não invasiva em pacientes acometidos por DGF e disfunção aguda do enxerto. Os resultados evidenciaram expressão aumentada dessas moléculas nos grupos de pacientes com rejeição aguda e no grupo com rejeição aguda superposta à NTA, diferenciandoas de pacientes com NTA pura nefrotoxicidade por IC, IFTA e pacientes com biópsias protocolares normais. Como pacientes em DGF não têm atualmente um marcador não invasivo acurado de rejeição aguda, essa abordagem, se adequadamente confirmada em estudos longitudinais, será de grande utilidade clínica. ${ }^{28} \mathrm{Na}$ figura 4, é mostrado o gráfico de ampliação do mRNA e as quantificações para o gene da Perforina em uma porção dos pacientes arrolados nesse último estudo descrito.

Figura 4 - Comparação das tecnologias de microarranjos e PCR em tempo real identificando seus pontos fortes e fracos

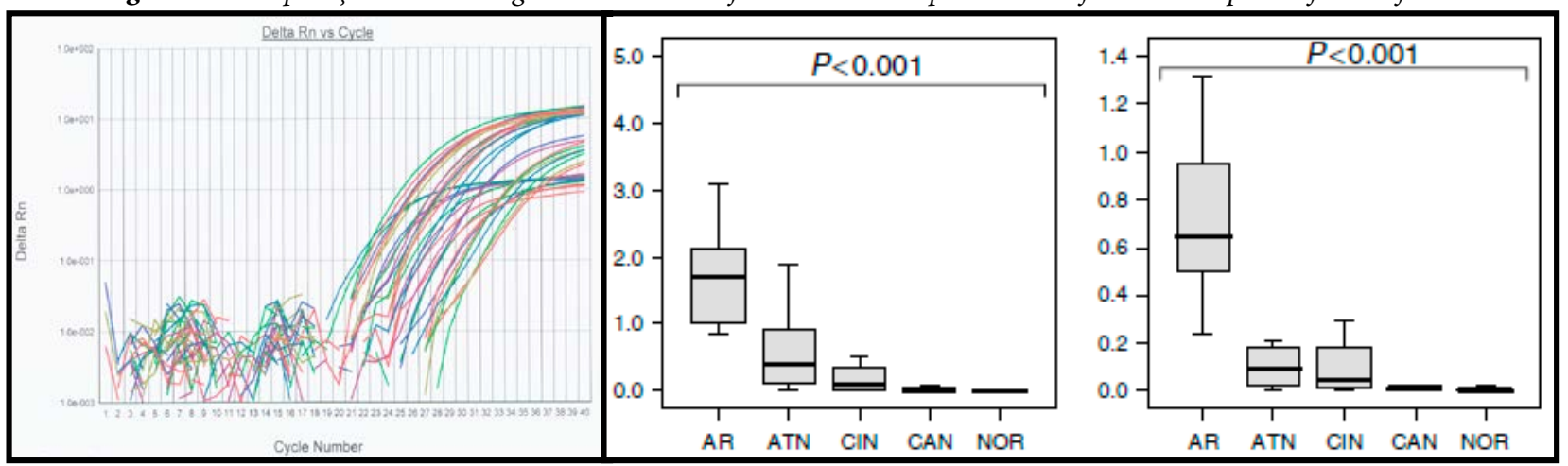

JBT J Bras Transpl. 2012;15:1651-1690 
Interessantemente, os estudos de marcadores moleculares demonstram que, nas duas condições RA e RASC, ocorre expressão aumentada dos mesmos genes relacionados ao ataque citolítico, sendo que na RA, esses mRNAs estão presentes em maior quantidade. ${ }^{38}$

Relatos preliminares de dois grandes consórcios internacionais, o Immune Tolerance Network (ITN) e Indexes of Tolerance (IOT) da União Europeia evidenciaram observações similares em relação à hiperexpressão de genes de células $\mathrm{B}$ em pacientes que desenvolveram tolerância, comparados com pacientes sob regime convencional de imunossupressão. ${ }^{39,40} \mathrm{Na}$ mesma direção, a baixa expressão de mRNA do marcador CD20 de células B foi observada em enxertos que perderam função como consequência de rejeição por células $\mathrm{T}$ ou mediada por anticorpos, se comparadas aos indivíduos/enxertos que tiveram um curso favorável. ${ }^{4}$

Dentre candidatos a potenciais marcadores, estudos recentes têm sugerido a avaliação deum subgrupo de células Tregulatórias(Tregs) chamado FoxP3 em nível protéico e transcripcional diretamente do enxerto e sua correlação com outros compartimentos como sangue periférico e urina. Estudos como o de Bestard et al., ${ }^{41}$ demonstraram que sob baixas condições inflamatórias, as Tregs parecem ter impacto favorável, exercendo papel regulatório nos infiltrados mononucleares intra-enxerto. Reciprocamente, quando a rejeição está se estabelecendo e, por conseguinte um importante processo inflamatório instaura-se no enxerto, esse subgrupo de células $\mathrm{T}$ só seria capaz de contrabalançar as funções efetoras destrutivas das células T citotóxicas ao invés de desempenhar uma função preventiva ou pró-tolerogênica. ${ }^{42}$

Nas rejeições mediadas por anticorpos (RMA) parece haver menos componentes regulatórios (Tregs e células $\mathrm{B}$ ) do que em rejeições mediadas por células T. Em estudo de Viklicky et al, pacientes que perderam o enxerto após RMA apresentaram uma ausência ainda maior de regulação (baixa expressão de FoxP3, RANTES, TGF-B1 e CD20). O melhor preditor de perda de enxerto dentro de 12 meses foi definido por baixa expressão de TGF-B1 e CD20. ${ }^{43}$

Avaliando fibrose tubulointersticial, Anglicheau e colaboradores avaliaram os níveis de mRNA de diversas moléculas na urina de pacientes com diagnóstico histológico de fibrose e de pacientes com biópsias normais. Um modelo composto pelos níveis de mRNA de quatro genes (vimentina, NKCC2, E-Caderina e 18S ribossomal) obteve $77 \%$ de sensibilidade e $87 \%$ de especificidade no diagnóstico de fibrose, reforçando a ideia da utilização dessa técnica como ferramenta diagnóstica não invasiva das agressões ao enxerto renal. ${ }^{44}$

Esses dados sugerem que a falta de uma contra-regulação adequada possa ser um elemento chave na patogênese de RMAs severas que resultam em perda do enxerto. ${ }^{4}$

\section{Microarranjos (Microarrays)}

Autilizaçãodemicroarranjos deDNA nabusca da identificaçãodeuma "assinatura molecular" para gerar perfis quantitativos de expressão de mRNA, permitindo a mensuração detalhada da expressão gênica em escala global tem sido amplamente empregada na investigação do complexo processo imunológico que sucede o transplante renal desde $2001 .{ }^{45} \mathrm{O}$ principal objetivo desses estudos é definir um grupo de genes de relevância diagnóstica que possa posteriormente ser utilizado como biomarcador através da técnica de PCR quantitativo.

A técnica de microarranjos de DNA foi mais recentemente utilizada em estudos com pacientes transplantados. Estudos utilizando essa tecnologia para estabelecer perfis de expressão de mRNA identificaram que a rejeição aguda está associada a importantes perturbações na expressão de múltiplos genes, incluindo aqueles envolvidos no ciclo celular, metabolismo e imunidade. ${ }^{32}$ No estudo pioneiro de Sarwal e colaboradores, demonstrou-se que esses testes moleculares poderiam evidenciar um painel de genes relacionados à resposta imunológica contra o enxerto. Nesse estudo, biópsias de pacientes com rejeição aguda que eram indistinguíveis por análise histológica convencional revelaram diferenças na expressão gênica associada a diferenças de componente imunológico e celular e curso clínico. Foram encontrados também aglomerados de células $\mathrm{B}$ em biópsias associadas com rejeição severa de enxerto, o que sugere um papel relevante das células B na rejeição aguda. ${ }^{46}$

Flechner e colaboradores publicaram o primeiro estudo utilizando essa metodologia em RNA, obtido de células mononucleares do sangue periférico, obtidas concomitante às amostras de biópsia. Seus resultados evidenciaram uma assinatura transcripcional capaz de diferenciar RA, disfunção aguda sem rejeição e transplantes com função estável sem histórico de rejeição. Uma peculiaridade desse estudo foi demonstrar que mesmo que essa assinatura molecular em sangue periférico tenha sido capaz de distinguir entre RA e pacientes com função estável, os padrões de expressão gênica foram muito diferentes dos padrões expressos no tecido. ${ }^{32}$

Brouard e colaboradores avaliaram a utilização da monitorização molecular como ferramenta não invasiva de tolerância operacional em pacientes transplantados renais. Esse estudo teve como objetivo a identificação de biomarcadores de tolerância operacional em sangue periférico, com intuito de utilizá-los para determinação da frequência desse estado em pacientes com função renal estável na presença de imunossupressores. Em um primeiro momento, foram segregados 49 genes relacionados à tolerância e posteriormente analisados por microarranjos e PCR em tempo real, e 33 deles conseguiram diferenciar os fenótipos de tolerância e rejeição crônica com alta especificidade e sensibilidade. A assinatura genética demonstrada sugeriu um padrão de redução de sinalização coestimulatória, quiescência imunológica, apoptose e respostas de células $\mathrm{T}$ de memória. Identificou-se no sangue periférico de transplantados renais um grupo de genes associados à tolerância operacional que pode vir a ser útil como ferramenta não invasiva para guiar a administração de medicação imunossupressora. ${ }^{33}$

Posteriormente, Reeve e colaboradores compararam a abordagem molecular com a histopatológica para o diagnóstico da rejeição aguda de transplantes renais. Esse estudo sugere que a abordagem molecular é mais fidedigna em representar o estado de agressão imunológica ao enxerto, uma vez que o diagnóstico histopatológico tem bases empíricas e observacionais (tratamento-dependente), sem um background explicativo da biologia mecanicista responsável pelo dano acarretado ao enxerto. Portanto, de acordo com os autores, as discordâncias entre as técnicas são esperadas e a metodologia molecular é mais poderosa e acurada para a avaliação do estado imune do paciente. A significância desses resultados no contexto da monitorização de pacientes submetidos a transplante renal pode explicar a falha de mais de uma década de trabalhos que analisaram em células do sangue periférico a ativação de antígenos baseada nos achados em biópsias de enxertos com rejeição e outros modelos imunes. É possível que o perfil de expressão gênica dos linfócitos do sangue periférico represente a adequação da imunossupressão, de tal forma que em pacientes que venham a rejeitar, reflitam a imunossupressão insuficiente, comparados com pacientes transplantados com função renal estável sem mecanismos operantes de agressão aloimune. ${ }^{26}$

$\mathrm{Na}$ metodologia dos microarranjos, o fato de se demonstrar que os 
transcritos ocorrem de maneira coordenada sugere que um limitado número de transcritos de genes seja necessário para a classificação de rejeição versus não rejeição. Por fim, um fato muito importante a ser considerado ao se desenhar uma ferramenta não invasiva para monitorização do enxerto é sua aplicabilidade. Atualmente, as análises por microarranjos ainda são muito onerosas, demoradas e sua avaliação estatística costuma ser muito mais complexa e de difícil resolução para utilização na rotina clínica, onde a análise de alguns genes de interesse por PCR em tempo real parece ser uma abordagem mais viável e recomendável. ${ }^{25}$ É importante mencionar que a reprodutibilidade de genes diferencialmente expressos pode ser afetada por vários fatores como a metodologia, diferenças inerentes entre os indivíduos e populações e e escolha delimiares, faltando ainda uma padronização e reprodutibilidade intra e inter laboratórios. ${ }^{4}$

\section{MicroRNAs}

Outro importante avanço na biologia celular foi a descoberta dos microRNAs (miRNAs); o primeiro, lin-4, foi identificado em 1993 por Lee e colaboradores, através de um estudo genético em nematódeos Caenorhabditis elegans, onde foi observada a capacidade de um miRNA alterar a expressão de determinado gene (lin-14). ${ }^{47,48}$ Quase uma década depois, no ano de 2000, um segundo miRNA (let-7) foi descoberto, e com ele foi vista outra característica relevante dos miRNAs: a conservação deles através das espécies. ${ }^{49}$

A ligação desses micros fragmentos de RNA com o RNA mensageiro (mRNA) e sua conservação através das espécies atraiu a atenção de pesquisadores, expandindo a pesquisa nessa área. ${ }^{48,50}$ Atualmente, centenas já foram clonados e previstos pela bioinformática. Estimase que o genoma humano contém em torno de 800-1000 miRNAs, sendo parte comum aos primatas. ${ }^{50}$

MicroRNAs são codificados por genes específicos, expressos no núcleo e submetidos a várias etapas de processamento até atingir sua forma madura, que varia de 19 a 25 nucleotídeos. A parte funcional é incorporada ao complexo silenciador induzido por RNA (RISC), composto por múltiplas proteínas que guiam a maquinaria silenciadora para o RNA mensageiro alvo, inibindo a tradução ou promovendo sua degradação. ${ }^{51}$

Atualmente, persiste uma lacuna no conhecimento dos mecanismos que fazem um miRNA escolher silenciar ou degradar seus alvos, visto que comprovadamente, um único miRNA pode inibir vários mRNA e a expressão de um único mRNA pode ser regulada por vários miRNAs distintos que atuam em conjunto..$^{51-53}$ Os miRNAs regulam seus genes alvos através de dois mecanismos: por repressão translacional ou por degradação do RNA mensageiro. Estima-se que pelo menos metade dos mRNAs expressos podem ser regulados por miRNAs. ${ }^{54}$

Esses pequenos fragmentos de RNA demonstram ter controle de processos como desenvolvimento, proliferação celular, diferenciação, apoptose, metabolismo e oncogênese. Apesar de se saber pouco sobre o processo de regulação dos miRNAs, sabe-se que a desregulação desses pode levar à perturbação e supressão de genes que operam na sinalização de cascatas intracelulares, levando a condições de doença ou de sua progressão. ${ }^{51-53}$

Diferentes estudos sugerem que os miRNAs participam ativamente da regulação e do desenvolvimento de células imunes. ${ }^{51-53}$

Já foram identificados miRNAs específicos que apresentam significativo impacto na diferenciação de células $\mathrm{B}$ e $\mathrm{T}$ e no processo celular necessário para a imunidade inata e adaptativa, incluindo inflamação, sinalização via TCR e receptores de células "toll-like" (TLR), produção de citocinas, da função celular das células Treg e apresentação de antígenos. ${ }^{51}$
No transplante renal, uma questão crítica e não resolvida é a base mecânica para as principais perturbações na expressão gênica durante um episódio de rejeição. Em um estudo, Sui e colaboradores compararam níveis de expressão de miRNAs em biópsias de pacientes submetidos a transplante renal que desenvolveram quadro de rejeição aguda e amostras de rins normais para averiguar a existência de relação entre miRNAs e rejeição aguda. O estudo identificou 71 miRNAs e desses, 20 miRNAs possuíam expressão diferenciada, sendo que 12 tinham seus níveis diminuídos e oito aumentados, quando comparados a pacientes com função renal normal. ${ }^{55}$

Em seguida, Anglicheau e colaboradores investigaram a associação de rejeição aguda com alterações significativas na expressão de miRNAs em tecido de enxertos renais e observaram se esses padrões de expressão intraenxerto de miRNAs seriam suficientes para diagnosticar rejeição aguda e predizer a função renal. Como resultado, encontrou-se que determinados miRNAs (miR-142-5p, miR-155 e miR-223) que estão hiperexpressos em biópsias com RA estão também presentes em altos níveis em células mononucleares do sangue periférico em comparação com os miRNAs hipoexpressos (miR-30a-3p, miR-10b ou let-7c) em biópsias sem RA. Outro achado importante desse estudo foi que dos 53 miRNAs diferencialmente expressos entre biópsias de RA e normais, 43 encontravam-se hipoexpressos e somente 10 estavam hiperexpressos. ${ }^{52}$

Shan e colaboradores revisaram o papel dos miRNAs nas células do sistema imune, com o objetivo de encontrar potenciais biomarcadores para transplantes de órgãos sólidos. Foram evidenciados marcadores imunológicos como o miR-181a que está relacionado com a modulação da sensibilidade de células $\mathrm{T}$ através da alteração do sinal do TCR, assim, é possível supor que a diminuição da expressão do miR-181a conduziria à redução da sinalização dos TCR e da atividade das células T ao aloantígeno. Outro marcador citado nesta revisão é o miR-142-3p, que está relacionado com a função das células Treg, tendo sua expressão regulada direta ou indiretamente pelo gene FOXP3, que quando a reprime, conduz um aumento na produção de AMP cíclico, transferindo-o para células TCD4+ convencionais causando supressão das Tregs. ${ }^{56}$

Um terceiro marcador citado por Shan e que foi bastante enfatizado é o miR-155, que está relacionado com várias partes do sistema imune. Esse miRNA está envolvido com a função das células dendríticas, apresenta um efeito anti-inflamatório, participa da resposta das células $\mathrm{T}$ e está caracterizado como regulador de resposta de células $B .{ }^{56}$

Em concordância com o estudo citado, outro autor, Barnejee e colaboradores encontraram evidências de que o miR-155 é capaz de inibir a expressão do sinalizador do receptor de interferon- $\gamma$ (IFN- $\gamma \mathrm{Ra}$ ), sugerindo que esse miRNA pode servir como um regulador rápido e reversível para células que estão submetidas à diferenciação antes da estabilização do gene, influenciando diretamente a diferenciação de células TCD4+ e contribuindo para a diferenciação das células T helper tipo1..$^{57}$

Visto o potencial dos miRNAs, pesquisadores têm procurado não só marcadores intra-enxerto, mas também o reflexo deles em células do sangue periférico e urina. Lorenzen e colaboradores testaram a hipótese que miRNAs encontrados no sedimento urinário de pacientes com rejeição aguda e outras alterações poderiam não só servir como marcadores, mas também como preditores da sobrevida do enxerto. Foram testados 81 pacientes, para os miR-10a, miR$10 \mathrm{~b}$ e miR-210 detectados na urina, encontrando-se resultados significativos, principalmente para o miR-210 que, entre outras 
características, está diminuído em pacientes transplantados renais com rejeição aguda, além de ser capaz de prever o declínio do índice de filtração glomerular, um anos após o transplante. Postula-se assim que o miR-210 seja um potencial marcador para rejeição renal aguda e preditor da função do enxerto em longo prazo. ${ }^{58}$

Micro-RNAs estão profundamente envolvidos com eventos que determinam rejeição, tolerância e manutenção da homeostase, além dos padrões de expressão de miRNA e dos seus níveis estarem altamente relacionados com a diferenciação de linfócitos e sua ativação. A expressão gênica de alguns miRNAs pode representar o comportamento fisiológico após um transplante, detectando precocemente alterações que indiquem rejeição ou desvios no comportamendo celular.

\section{Perspectivas no uso dos testes moleculares em transplante renal}

Existe a expectativa de que os microarranjos venham a desempenhar papel crucial no transplante de órgãos em assuntos relacionados à identificação de mecanismos moleculares de rejeição aguda, injúria crônica, efeito de toxicidade das drogas imunossupressoras e tolerância. É também esperado que eles ajudem a identificar novos alvos de drogas para um tratamento com imunossupressores pós-transplante mais personalizado. Mais importante, espera-se que os microarranjos ajudem a definir biomarcadores para uso não invasivo e para o diagnóstico clínico de rejeição e de tolerância. $\mathrm{Na}$ abordagem clínica, existem duas razões principais para que se utilize um número pequeno de genes para monitoramento clínico por RT-PCR. A primeira é o custo; a RT-PCR é consideravelmente menos onerosa para testar um número restrito de genes, podendo ser realizada rapidamente e na maior parte dos laboratórios. Os microarranjos, que utilizam tecnologia mais cara são úteis para testar múltiplos genes, em geral centenas. A segunda diz respeito à análise dos resultados com as duas metodologias. Os microarranjos são complexos e requerem muito tempo e pessoal altamente treinado para sua interpretação, ao passo que os dados provenientes da RT-PCR são de análise consideravelmente mais simples e rápida. Adicionalmente, a RTPCR é mais sensível em detectar pequenas mudanças na expressão gênica. A comparação das tecnologias de microarranjos e PCR em tempo real identificando seus pontos fortes e fracos foi proposta por Kahtri e colaboradores e está apresentada na figura $5 .{ }^{59}$

Figura 5. Comparação das tecnologias de Microarranjos e PCR em Tempo Real

\begin{tabular}{|l|l|}
\hline \multicolumn{1}{|c|}{ Microarranjos } & \multicolumn{1}{c|}{ PCR em Tempo Real } \\
\hline $\begin{array}{l}\text { - Custo efetivo no rastreamento de milhares de genes. } \\
\text { Muito dispendioso para rastreamento de apenas dezenas de } \\
\text { genes }\end{array}$ & $\begin{array}{l}\text { - Custo efetivo em testar no máximo algumas dezenas de genes. } \\
\text { Cara e consome tempo para testar centenas de genes }\end{array}$ \\
\hline $\begin{array}{l}\text { - Tecnologia relativamente nova e requer expertise na análise } \\
\text { dos dados }\end{array}$ & $\begin{array}{l}\text { - Análise de dados simplificada e de fácil aplicabilidade na rotina } \\
\text { clínica }\end{array}$ \\
\hline $\begin{array}{l}\text { - Baixa sensibilidade devido a não detecção de transcritos pouco } \\
\text { abundantes na amostra. }\end{array}$ & $\begin{array}{l}\text { - Alta sensibilidade permite a detecção de transcritos pouco } \\
\text { abundantes em uma amostra. }\end{array}$ \\
\hline $\begin{array}{l}\text { - Baixa especificidade por hibridização cruzada, erros no } \\
\text { desenho das sondas. } \\
\text { Limitada na detecção de splice-alternativos. }\end{array}$ & $\begin{array}{l}\text { - Alta especificidade; possibilidade de desenhar primers para } \\
\text { identificação de transcritos splice-variantes }\end{array}$ \\
\hline
\end{tabular}

Embora o potencial impacto clínico das assinaturas de expressão gênica que podem predizer a RA e monitorar a imunossupressão seja claro, as possíveis contribuições para entendimento da biologia do transplante também são importantes considerações. Por conseguinte, o objetivo máximo da assinatura da expressão gênica é identificar genes específicos e associá-los a rotas de mecanismos celulares mediadores de rejeição, lesão e reparo tecidual, imunossupressão e tolerância. Com o conhecimento dos mecanismos de ação é possível que se desenvolvam novas drogas e abordagens mais eficazes que permitam a monitorização segura do curso clínico e de eventuais estados de tolerância ao enxerto. ${ }^{53}$

O desenvolvimento de técnicas moleculares capazes de fornecer um painel da atividade imunológica responsável pela agressão ao enxerto de forma não invasiva sugere a possibilidade futura da otimização e individualização do tratamento com drogas imunossupressoras.

Situações clínicas nas quais a monitorização dos processos nocivos ao enxerto é feita por biópsias, como a DGF, RASC, IFTA, entre outras, poderão vir a ser diagnosticadas por métodos moleculares não invasivos.

No entanto, existem diversas premissas a serem cumpridas para que os testes moleculares possam alcançar a arena clínica. Especificamente, os testes deverão: [1] ser avaliados em diferentes coortes de pacientes; [2] ser avaliados em séries de pacientes consecutivos com múltiplas patologias para permitir a verdadeira determinação de seus parâmetros diagnósticos; [3] ser reproduzidos por grupos independentes; [4] ser avaliados longitudinalmente para determinar a habilidade de um dado ensaio de detectar processos patológicos precocemente e tardiamente pós-transplante, assim como avaliar seu comportamento em condições intervenientes; [5] demonstrar que o teste candidato retorna aos valores basais com terapia efetiva. Além de satisfazer esses critérios básicos, um teste útil também deve ser capaz de detectar níveis sub-clínicos de agressão para que a intervenção precoce seja uma opção potencial..$^{25}$ 


\section{ABSTRACT}

Kidney transplantation is the treatment of choice for many end-stage kidney disease patients. Acute rejection remains a significant complication, and the graft biopsy is still the gold diagnostic standard. As it is invasive and potentially harmful, there are searches for new markers to diagnose such condition. Non-invasive diagnostic tools have several advantages mainly including possibility of frequent and sequential use to easily assess the immune status of the receptor. This review presents the methods and advantages of the molecular approaches currently used in researching kidney transplantation, real time polymerase chain reaction, DNA microarrays, and more recently, micro-RNAs analyzes. It is expected that microarrays and micro-RNAs may attain a crucial role to the organ transplantation in matters related to the identification of molecular mechanisms of acute rejection, chronic injury, effect of immunosuppressive drug toxicity and tolerance. The development of molecular techniques capable of noninvasively provide a panel for the immunological activity mediating injury to the graft suggests possibility of optimization and individualization of the immunosuppressive therapy. For this review, we used searching tools on international databases (PubMed, Web of Knowledge) through the descriptors "Kidney transplantation", "Graft Rejection" and "Diagnostic Techniques and Procedures". We selected only studies from indexed journals and referred to studies of major clinical or historical importance in the area.

Keywords: Kidney Transplantation; Graft Rejection; Diagnostic Techniques and Procedures.

\section{REFERÊNCIAS:}

1. Nankivell B, Alexander S. Rejection of the Kidney Allograft. N Engl J Med. 2010;363;15

2. Colvin RB, Cohen AH, Saiontz C, Bonsib S, Buick M, Burke B, et al. Evaluation of pathologic criteria for acute renal allograft rejection: reproducibility, sensitivity, and clinical correlation. J Am Soc Nephrol. 1997;8:1930-41.

3. Biomarkers definition working group. Biomarkers and surrogate endpoints: preferred definitions and conceptual framework. Clin Phamacol Ther. 2001;69:89-95.

4. Bestard O, Cruzado JM, la Franquesa M, Grinyó JM. Biomarkers in renal transplantation. Curr Opin Organ Transplant. 2010;15:467-73.

5. Azuaje F, Devaux Y, Wagner D. Challenges and standards in reporting diagnostic and prognostic biomarker studies. Clin Transl Sci. 2009;2:156-61.

6. Walsh PT, Strom TB, Turka LA. Routes to transplant tolerance versus rejection: the role of citokynes. Immunity. 2004;20:121-31.

7. Muthukumar T, Ding R, Dadhania D, Medeiros M, Li B, Sharma VK, Hartono $\mathrm{C}$, et al. Serine proteinase inhibitor-9, an endogenous blocker of granzyme $\mathrm{B} /$ perforin lytic pathway, is hyperexpressed during acute rejection of renal allografts. Transplantation. 2003;75:1565-70.

8. Muthukumar T, Dadhania D, Ding R, Snopkowski C, Naqvi R, Lee JB, et al. Messenger RNA for FOX P3 in the urine of renal-allograft recipients. N Engl J Med. 2005,353:2342-51.

9. Gloor J, Cosio F, Lager DJ, Stegall MD. The spectrum of antibodymediated renal allograft injury: implications for treatment. Am J Transplant. 2008;8:1367-73.

10. Bettelli E, Oukka M, Kuchroo V. TH-17 cells in the circle of immunity and autoimmunity Nature Immunology. 2007;8:345-50

11. Jang HR, Ko GJ, Wasowska BA, Rabb H. The interaction between ischemia reperfusion and immune responses in the kidney. J Mol Med. 2009;87:859-64.

12. Rouvier E, Luciani MF, Mattei MG, Denizot F, Golstein P. CTLA-8, cloned from an activated $\mathrm{T}$ cell, bearing $\mathrm{AU}$ rich messenger RNA instability sequences, and homologous to a herpesvirus saimiri gene. J. Immunol. 1993;150: 5445-56.

13. Weaver CT, Hatton RD, Mangan PR, Harrington LE. IL-17 family cytokines and the expanding diversity of effector $\mathrm{T}$ cell lineages. Annu Rev Immunol. 2007;25:821-52.

14. Torchinsky, MB, Garaude J, Martin AP, Blander JM. Innate immune recognition of infected apoptotic cells directs $\mathrm{T}(\mathrm{H}) 17$ cell differentiation. Nature. 2009;458:78-82.

15. Peck A, Mellins ED. Precarious Balance: Th17 Cells in Host Defense. Infect Immun. 2010;78(1):32-8

16. Caldwell CC, Okaya T, Martignoni A, Husted T, Schuster R, Lentsch AB. Divergent functions of CD4-T lymphocytes in acute liver inflammation and injury after ischemia-reperfusion. Am J Physiol Gastrointest Liver Physiol. 2005;289:G969-G976.

17. Van KC, Boonstra JG, Paape ME, Fossiez F, Banchereau J, Lebecque S, et al. Interleukin-17 activates human renal epithelial cells in vitro and is expressed during renal allograft rejection. J Am Soc Nephrol. 1998;9:1526-34.
18. Solez K, Colvin RB, Racusen LC, Haas M, Sis B, Mengel M, et al. Banff 07 classification of renal allograft pathology: updates and future directions. Am J Transplant. 2008;8:753-60.

19. Gaber LW, Moore LW, Alloway RR, Flax SD, Shokouh-Amiri MH, Schroder $\mathrm{T}$, et al. Correlation between Banff classification, acute renal rejection scores and reversal of rejection. Kidney Int. 1996;49:481-7.

20. Marcussen N, Olsen TS, Benediktsson H, Racusen L, Solez K. Reproducibility of the Banff classification of renal allograft pathology. Interand intraobserver variation. Transplantation. 1995;60:1083-9.

21. Nankivell BJ, Borrows RJ, Fung CL, O'Connell PJ, Allen RDM, Chapman JR: Natural history, risk factors, and impact of subclinical rejection in kidney transplantation. Transplantation. 2004;78:242-9.

22. Rush DN, Henry SF, Jeffery JR, Schroeder TJ, Gough J. Histological findings in early routine biopsies of stable renal allograft recipients. Transplantation. 2004;57:208-11.

23. Hirsch HH, Brennan DC, Drachenberg CB, Ginevri F, Gordon J, Limaye $\mathrm{AP}$, et al. Polyomavirus-associated nephropathy in renal transplantation: interdisciplinary analyses and recommendations. Transplantation. 2005;79:1277-86.

24. Nankivell BJ, Borrows RJ, Fung CL, O'Connell PJ, Allen RDM, Chapman JR: The natural history of chronic allograft nephropathy. N Engl J Med. 2003;349:2326-33.

25. Nickerson P. Post-transplant monitoring of renal allografts: are we there yet? Curr Opin Immunol. 2009;21:563-8.

26. Reeve J, Einecke G, Mengell M, Sis B, Kayser N, Kaplan B, et al. Diagnosing rejection in renal transplants: a comparision of molecular- and histopathology-based approaches. Am J Transplant. 2009;9:1-9.

27. Strom TB. Rejection - More than the eye can see. N Engl J Med. 2005, $353 ; 2394-96$.

28. Aquino-Dias E, Joelsons G, da Silva DM, Berdichevski RH, Ribeiro AR, Veronese FJ, et al. Non-invasive diagnosis of acute rejection in kidney transplants with delayed graft function. Kidney Int. 2008;73:877-84.

29. Vasconcellos LM, Schachter AD, Zheng XX, Vasconcellos LH, Shapiro M, Harmon WE, et al. Cytotoxic lymphocyte gene expression in peripheral blood leukocytes correlates with rejecting renal allografts. Transplantation. 1998;66:5626.

30. Li B, Hartono C, Ding R, Sharma VK, Ramaswamy R, Qian B, et al. Noninvasive diagnosis of renal-allograft rejection by measurement of messenger RNA for perforin and granzymeB in urine. N Engl $\mathrm{J}$ Med. 2001;344:947-54.

31. Renesto PG, Ponciano VC, Cenedeze MA, Saraiva-Câmara NO, PachecoSilva A. High expression of Tim-3 mRNA in urinary cells from kidney transplant recipients with acute rejection. Am J Transplant. 2007;7:16615.

32. Flechner SM, Kurian SM, Head SR, Sharp SM, Whisenant TC, Zhang J, et al. Kidney transplant rejection and tissue injury by gene profiling of biopsies and peripheral blood lymphocytes. Am J Transplant. 2004;4:1475-89. 
33. Brouard S, Mansfield E, Braud C, Li L, Giral M, Hsieh SC, et al Identification of a peripheral blood transcriptional biomarker panel associated with operational renal allograft tolerance. Proc Natl Acad Sci U S A. 2007;104:15448-53.

34. Livak KJ, Flood SJ, Marmaro J, Giusti W, Deetz K. Oligonucleotides with fluorescent dyes at opposite ends provide a quenched probe system useful for detecting PCR product and nucleic acid hybridization. PCR Methos Appl. 1995;4:357-62.

35. Livak KJ, Schmittgen TD. Analysis of relative gene expression data using real-time quantitative PCR and the 2- $\Delta \Delta$ Ct Method. Methods. 2001;25:4028.

36. Bustin SA. Absolute quantification of mRNA using real-time reverse transcription polymerase chain reaction assays. J Mol Endocrinol. 2000;25:169-93.

37. Manfro RC, Aquino-Dias EC, Joelsons G, Nogare AL, Carpio VN, Gonçalves LF. Noninvasive Tim-3 messenger RNA evaluation in renal transplant recipients with graft dysfunction. Transplantation. 2008,86:1869-74.

38. Dias ECA, Veronese FJV, Gonçalves LFS, Manfro RC. Molecular markers in subclinical acute rejection of renal transplants. Clin Transplant. 2004;18:281-7.

39. Hernandez-Fuentes M, Sawitzki B, Perucha E, et al. Identification of immune tolerance in renal transplants. Am J Transplant. 2008;8(Suppl 2):292.

40. Newell KA, Asare A, Kirk AD, Gisler T, Bourcier K, Suthanthiran M, et al. Identification of a B cell signature associated with renal transplant tolerance in humans. J Clin Invest. 2010;120:1836-47.

41. Bestard O, Cruzado JM, Rama I, Torras J, Gomà M, Serón D, et al. Presence of FoxP3+ regulatory $\mathrm{T}$ cells predicts outcome of subclinical rejection of renal allografts. J Am Soc Nephrol. 2008;19:2020-6.

42. Bunnag S, Allanach K, Jhangri GS, Sis B, Einecke G, Mengel M, et al FOXP3 expression in human kidney transplant biopsies is associated with rejection and time post transplant but not with favorable outcomes. Am J Transplant. 2008;8:1423-33.

43. Viklicky O, Hribova P, Volk HD, Slatinska J, Petrasek J, Bandur S, et al. Molecular phenotypes of acute rejection predict kidney graft prognosis. Am Soc Nephrol. 2010;21:173-80.

44. Anglicheau D, Muthukumar T, Hummel A, Ding R, Sharma VK, Dadhania $\mathrm{D}$, et al. Discover and validation of a molecular signature for the noninvasive diagnosis of human renal allograft fibrosis. Transplantation. 2012 Jun 15;93(11):1136-46
45. Jun AS, Liu SH, Koo EH, Do DV, Stark WJ, Gottsch JD. Microarray analysis of gene expression in human donor corneas. Arch Ophthalmol. 2001;119:1629-34.

46. Sarwal M, Chua MS, Kambham N, Hsieh SC, Satterwhite T, Masek M, et al. Molecular heterogeneity in acute renal allograft rejection identified by DNA microarray profiling. N Eng J Med. 2003;349:125-38.

47. Lee RC, Feinbaum RL, Ambros V. The C. elegans heterochronic gene lin4 encodes small RNAs with antisense complementarity to lin-14. Cell. 1993;75:843-54.

48. Liu J. Control of protein synthesis and mRNA degradation by microRNAs. Curr Opin Cell Biol. 2008;20:214-21.

49. Reinhart BJ, Slack FJ, Basson M, Pasquinelli AE, Bettinger JC, Rougvie $\mathrm{AE}$, et al. The 21-nucleotide let-7 RNA regulates developmental timing in Caenorhabditis elegans. Nature. 2000;403:901-6.

50. Bartel DP. MicroRNAs: genomics, biogenesis, mechanism, and function. Cell 2004;116:28;97

51. Harris A, Krams SM, Martinez OM. MicroRNAs as Immune Regulators: Implications for Transplantation. Am J Transplant. 2010;10:71319.

52. Anglicheau D, Sharma VK, Ding R, Hummel A, Snopkowski C, Dadhania $\mathrm{D}$, et al. MicroRNA expression profiles predictive of human renal allograft status. Proc Natl Acad Sci USA. 2009;106:5330-5.

53. Hartono C, Muthukumar T, Suthanthiran M. Noninvasive diagnosis of acute rejection of renal allografts. Curr Opin Organ Transplant. 2010;15:35-41.

54. Bartel DP. MicroRNAs: target recognition and regulatory functions. Cell. 2009;136:215-33.

55. Sui W, Dai Y, Huang Y, Lan H, Yan Q, Huang H. Microarray analysis of MicroRNA expression in acute rejection after renal transplantation. Transpl Immunol. 2008; 19:81-5.

56. Shan J, Feng L, Luo L, Wu W, Li C, Li S, et al. MicroRNAs: potential biomarker in organ transplantation. Transpl Immnunol. 2011;24:210-5.

57. Banerjee A, Schambach F, DeJong CS, Hammond SM, Reiner SL. MicroRNA-155 inhibits IFN-gamma signaling in CD4+ T cells. Eur J Immunol. 2010;40:225-31

58. Lorenzen JM, Volkmann I, Fiedler J, Schmidt M, Scheffner I, Haller H, et al. Urinary miR-210 as a mediator of acute T-cell mediated rejection in renal allograft recipients. Am J Transplant. 2011;11:2221-7.

59. Khatri P, Sarwal MM. Using gene arrays in diagnosis of rejection. Curr Opin Organ Transplant. 2009;14:34-9. 